Atmos. Chem. Phys., 3, 2015-2023, 2003

www.atmos-chem-phys.org/acp/3/2015/

\title{
Heavy hydrogen in the stratosphere
}

\author{
T. Röckmann ${ }^{1}$, T. S. Rhee ${ }^{2}$, and A. Engel $^{3}$ \\ ${ }^{1}$ Max-Planck-Institut für Kernphysik, Bereich Atmosphärenphysik, Saupfercheckweg 1, 69117 Heidelberg, Germany \\ ${ }^{2}$ Max-Planck-Institut für Chemie, Chemie der Atmosphäre, Becherweg 27, 55122 Mainz, Germany \\ ${ }^{3}$ Institut für Meteorologie und Geophysik, Universität Frankfurt, Georg Voigt Str. 14, 60325 Frankfurt, Germany
}

Received: 14 July 2003 - Published in Atmos. Chem. Phys. Discuss.: 25 July 2003

Revised: 24 October 2003 - Accepted: 5 November 2003 - Published: 19 November 2003

\begin{abstract}
We report measurements of the deuterium content of molecular hydrogen $\left(\mathrm{H}_{2}\right)$ obtained from a suite of air samples that were collected during a stratospheric balloon flight between 12 and $33 \mathrm{~km}$ at $40^{\circ} \mathrm{N}$ in October 2002. Strong deuterium enrichments of up to $400 \%$ versus Vienna Standard Mean Ocean Water (VSMOW) are observed, while the $\mathrm{H}_{2}$ mixing ratio remains virtually constant. Thus, as hydrogen is processed through the $\mathrm{H}_{2}$ reservoir in the stratosphere, deuterium is accumulated in $\mathrm{H}_{2}$. Using box model calculations we investigated the effects of $\mathrm{H}_{2}$ sources and sinks on the stratospheric enrichments. Results show that considerable isotope enrichments in the production of $\mathrm{H}_{2}$ from $\mathrm{CH}_{4}$ must take place, i.e., deuterium is transferred preferentially to $\mathrm{H}_{2}$ during the $\mathrm{CH}_{4}$ oxidation sequence. This supports recent conclusions from tropospheric $\mathrm{H}_{2}$ isotope measurements which show that $\mathrm{H}_{2}$ produced photochemically from $\mathrm{CH}_{4}$ and non-methane hydrocarbons must be enriched in deuterium to balance the tropospheric hydrogen isotope budget. In the absence of further data on isotope fractionations in the individual reaction steps of the $\mathrm{CH}_{4}$ oxidation sequence, this effect cannot be investigated further at present. Our measurements imply that molecular hydrogen has to be taken into account when the hydrogen isotope budget in the stratosphere is investigated.
\end{abstract}

\section{Introduction}

Molecular hydrogen $\left(\mathrm{H}_{2}\right)$, methane $\left(\mathrm{CH}_{4}\right)$ and water vapor $\left(\mathrm{H}_{2} \mathrm{O}\right)$ are the three main hydrogen reservoirs in the stratosphere. Once an air parcel has entered the stratosphere, hydrogen can only be cycled between these reservoirs (as well as several short-lived species like $\mathrm{OH}, \mathrm{HO}_{2}$ or $\mathrm{HCHO}$ ), since there are no net sources or sinks of hydrogen. Thus, the total

Correspondence to: T. Röckmann

(T.Roeckmann@mpi-hd.mpg.de) hydrogen content $\chi\left(\mathrm{H}_{2}\right)=2 \chi\left(\mathrm{CH}_{4}\right)+\chi\left(\mathrm{H}_{2}\right)+\chi\left(\mathrm{H}_{2} \mathrm{O}\right)$, where $\chi$ denotes the mixing ratio, is generally constant in the stratosphere. Significant redistribution of total hydrogen can only occur during major dehydration events, which are very rare. During these events, ice crystals grow sufficiently large to fall to lower altitudes, where they can evaporate again.

Among the three stratospheric hydrogen reservoirs, $\mathrm{H}_{2}$ is known to show virtually no changes in its mixing ratio in the stratosphere up to $40 \mathrm{~km}$ (Ehhalt et al., 1977). It is not that $\mathrm{H}_{2}$ does not participate in the photochemical hydrogen cycling, but its production and loss rates are virtually identical. In the stratosphere, the most significant in situ source of $\mathrm{H}_{2}$ is $\mathrm{CH}_{4}$ oxidation (Fig. 1). Several reaction steps lead to the production of formaldehyde ( $\mathrm{HCHO})$, from which $\mathrm{H}_{2}$ can be formed by photolysis. Figure 1 also shows that at the most 2 of the 4 hydrogen atoms in a methane molecule can finally end up in $\mathrm{H}_{2}$. One $\mathrm{H}$ atom is lost in the initial abstraction reaction, a second one in the reaction step $\mathrm{CH}_{3} \mathrm{O}+\mathrm{O}_{2} \rightarrow \mathrm{HCHO}+\mathrm{HO}_{2}$. The fraction of the remaining two $\mathrm{H}$ atoms that form $\mathrm{H}_{2}$ through $\mathrm{HCHO}$ photolysis is dependent on the relative strengths of $\mathrm{HCHO}$ oxidation vs. photolysis and on the relative strength of the two photolysis channels (Fig. 1). The main stratospheric sinks of $\mathrm{H}_{2}$ are reaction with $\mathrm{OH}$ and $\mathrm{O}\left({ }^{1} \mathrm{D}\right)$ radicals. Reaction with $\mathrm{Cl}$ is a minor sink.

The end product of both the $\mathrm{CH}_{4}$ and the $\mathrm{H}_{2}$ oxidation chains is $\mathrm{H}_{2} \mathrm{O}$. This means that changes in atmospheric mixing ratios of both $\mathrm{CH}_{4}$ and $\mathrm{H}_{2}$ have a potential impact on water vapor concentrations in the stratosphere. It is known that the tropospheric increase in $\mathrm{CH}_{4}$ mixing ratios, which is well documented (Blake and Rowland, 1988; Dlugokencky et al., 1998; Etheridge et al., 1992), has contributed to, but can not entirely explain the observed increase in stratospheric water vapour (Engel et al., 1996; Oltmans and Hofmann, 1995). With $\mathrm{H}_{2}$ being projected as a major energy carrier in the future, emissions into the atmosphere during production, storage and transport of $\mathrm{H}_{2}$ are likely to increase (Tromp et 


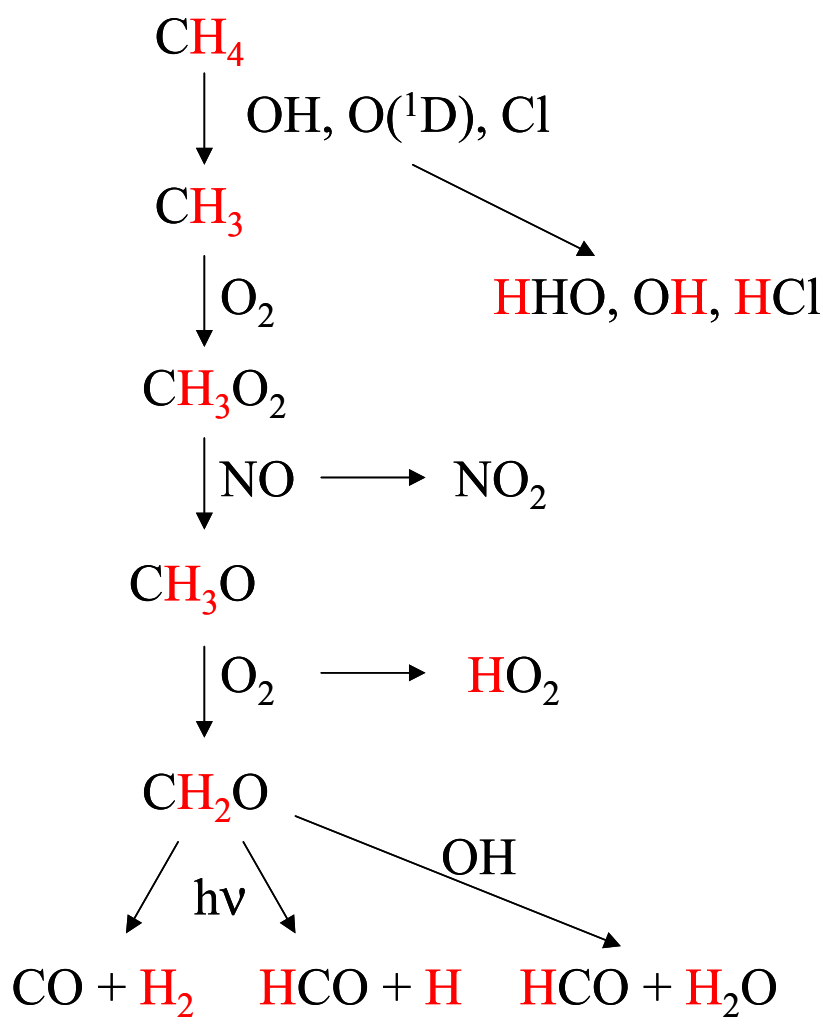

Fig. 1. Schematic diagram of the $\mathrm{CH}_{4}$ oxidation pathway that leads to $\mathrm{H}_{2}$ production. Out of the 4 hydrogen atoms initially present (marked in red), two end up in $\mathrm{H}_{2} \mathrm{CO}$ and are available for transfer into $\mathrm{H}_{2}$. The other two are transferred to other reaction products and eventually end up as water. In particular in these $\mathrm{H}$ abstraction steps large fractionations can occur if light hydrogen is removed preferentially.

al., 2003). This could cause a substantial increase in stratospheric $\mathrm{H}_{2} \mathrm{O}$ levels with severe implications for the energy balance of the earth (Forster and Shine, 2002), stratospheric temperatures (Forster and Shine, 2002), microphysical conditions in the stratosphere (Tromp et al., 2003) and stratospheric ozone levels (Evans et al., 1998).

Since the $\mathrm{H}_{2}$ mixing ratio in the lower and middle stratosphere is nearly constant with altitude, the net hydrogen cycling in the stratosphere can be regarded as a loss in methane and a production of water. Therefore, molecular hydrogen is not included in many studies that examine possible changes in the stratospheric hydrogen budget. However, during the stratospheric processing of $\mathrm{H}_{2}$ the isotopic composition may change although mixing ratios stay constant. This is particularly true for cycling between the three stratospheric hydrogen reservoirs, since their isotopic composition is very distinct. Water vapor, on its way from the surface to the tropopause, loses heavy isotopes in condensation processes and becomes depleted in heavy isotopes. Several studies now indicate that water enters the stratosphere with an approximate isotopic composition of $\delta \mathrm{D} \sim-670 \%$ (Kuang et al.,
2003). $\mathrm{CH}_{4}$ and $\mathrm{H}_{2}$ enter the stratosphere with their typical average tropospheric $\delta$ values of $\delta \mathrm{D}\left(\mathrm{CH}_{4}\right) \sim-86 \%$ o (Quay et al., 1999) and $\delta \mathrm{D}\left(\mathrm{H}_{2}\right) \sim 130 \%$ (Gerst and Quay, 2000; Rahn et al., 2002). Since both $\mathrm{CH}_{4}$ and $\mathrm{H}_{2}$ are strongly enriched in D compared to $\mathrm{H}_{2} \mathrm{O}$, it is expected that $\mathrm{H}_{2} \mathrm{O}$ formed via oxidation of these two gases will be enriched relative to the water that enters from the troposphere. Therefore the deuterium content of stratospheric $\mathrm{H}_{2} \mathrm{O}$ should increase as its concentration increases. Similarly, one might intuitively expect that $\mathrm{H}_{2}$ formed from $\mathrm{CH}_{4}$ should be isotopically light, because the $\mathrm{CH}_{4}$ is depleted in $\mathrm{D}$ relative to $\mathrm{H}_{2}$. In addition, a kinetic isotope effect in the $\mathrm{CH}_{4}$ sink further depletes the $\mathrm{CH}_{4}$ that is removed (see below). On the other hand, a similarly strong fractionation in the removal of $\mathrm{H}_{2}$ by $\mathrm{OH}(\mathrm{HH}$ is removed preferentially) enriches the remaining fraction of $\mathrm{H}_{2}$. Additional isotope effects are expected in the oxidation pathway (Gerst and Quay, 2001). The net effect on the deuterium content of $\mathrm{H}_{2}$ in the stratosphere is hard to estimate, because of the large differences in $\delta$ values between the hydrogen reservoirs and the kinetic fractionations involved. A first attempt to constrain the isotopic composition of stratospheric $\mathrm{H}_{2}$ from combined spectroscopic deuterium measurements on stratospheric water and methane (Irion et al., 1996), did not yield detailed information on $\delta \mathrm{D}\left(\mathrm{H}_{2}\right)$. Recently, Rahn et al. (2003) presented the first high-precision measurements of the deuterium content of molecular hydrogen from samples taken on the NASA ER-2 aircraft in the Arctic winter stratosphere, and found very strong deuterium enrichments. In this paper we extend those observations to lower latitudes and higher altitudes. We find that $\delta \mathrm{D}\left(\mathrm{H}_{2}\right)$ increases up to $400 \%$ at $33 \mathrm{~km}$ and $44^{\circ} \mathrm{N}$, and throughout the stratosphere $\delta \mathrm{D}\left(\mathrm{H}_{2}\right)$ correlates linearly with decreasing mixing ratios of methane, as found by Rahn et al. (2003).

\section{Experimental}

Mixing and isotope ratios of hydrogen (and a suite of other trace gases like $\mathrm{CH}_{4}$ and $\mathrm{N}_{2} \mathrm{O}$ ) were determined from whole air samples collected cryogenically during a stratospheric balloon flight. Details of the sampler are given in Schmidt et al. (1987). Although $\mathrm{H}_{2}$ does not condense at liquid Neon temperature, at which samples are collected, it enters the sampler entrained with the whole air flow and then cannot escape against the inflowing air under high flow conditions.

The deuterium content of $\mathrm{H}_{2}$ is measured by continuousflow isotope ratio mass spectrometry (CF-IRMS) using a method that has been recently developed. The method is similar to the one by Rahn et al. (2002), but does not require a Toepler pump for concentration of $\mathrm{H}_{2}$. Details of the method will be presented elsewhere (Rhee et al., manuscript submitted to Rapid Communications in Mass Spectrometry), and here we describe it in brief. An aliquot of an air sample is condensed onto the cold head $(\sim 40 \mathrm{~K})$ of a liquid Helium compressor. $\mathrm{H}_{2}$ does not condense at that temperature 


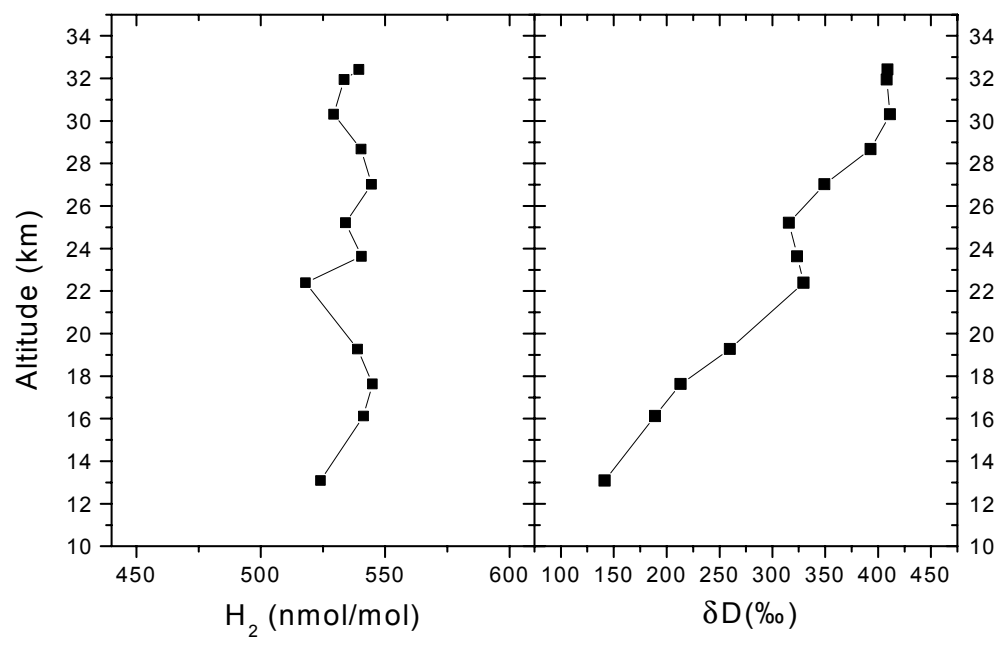

Fig. 2. Hydrogen mixing ratio and $\delta \mathrm{D}\left(\mathrm{H}_{2}\right)$ in the stratosphere as a function of altitude. Although the mixing ratio stays virtually constant, $\delta \mathrm{D}\left(\mathrm{H}_{2}\right)$ increases almost $300 \%$.

(neither do $\mathrm{He}$ and $\mathrm{Ne}$ ) and is subsequently flushed with a slow flow of Helium onto a cryogenic trap filled with molecular sieve. The temperature of the liquid nitrogen coolant is reduced by pumping on the head space. When the sample has been collected, it is transferred to a cryo-focus trap immersed in liquid nitrogen at the head of a molecular sieve capillary gas chromatography column. The hydrogen is then released onto the column and admitted to the mass spectrometer via an open split interface. The reproducibility of the isotope ratio measurement is presently about $\pm 3 \%$ as determined from multiple measurements of a laboratory reference gas. The accuracy was checked with commercial isotope standards (IsoTop, Messer Griesheim) with nominal isotope values of $-9.5 \%$ and $+205 \%$ and the mass spectrometer reference gas, whose isotopic ratio was determined at the University of Heidelberg on an isotope ratio mass spectrometer which is calibrated using international water standards.

In addition to the $\mathrm{D} / \mathrm{H}$ isotope ratio, $\mathrm{H}_{2}$ mixing ratios can be readily obtained from the combined peak areas of the two isotopologues. Results show good agreement with measurements carried out with a mercury oxide $\mathrm{H}_{2}$ detector (T. Wetter, personal communication).

Trace gas mixing ratios are reported in $\mathrm{nmol} / \mathrm{mol}\left(10^{-9}\right)$. The isotopic composition is expressed in $\delta$ notation as the relative deviation of the $\mathrm{D} / \mathrm{H}$ ratio in a sample (SA) from a standard $(\mathrm{ST}), \delta=\left((\mathrm{D} / \mathrm{H})_{\mathrm{SA}} /(\mathrm{D} / \mathrm{H})_{\mathrm{ST}}-1\right) * 1000 \%$. The international standard for hydrogen isotopes is Vienna Standard Mean Ocean Water (VSMOW) with an absolute D/H ratio of $(155.76 \pm 0.05) \cdot 10^{-6}$ (Hagemann et al., 1970). Kinetic fractionation factors in chemical reactions are expressed as the reaction rate of the heavy isotopologue relative to the light isotopologue, e.g., $\alpha_{\mathrm{HD}-\mathrm{sink}}=k(\mathrm{HD}-\mathrm{removal}) / k(\mathrm{HH}-$ removal).

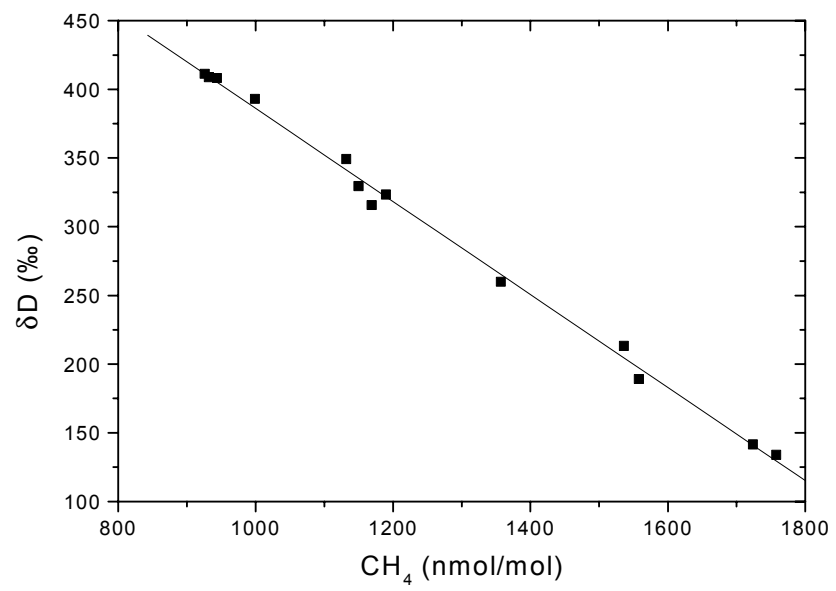

Fig. 3. $\delta \mathrm{D}\left(\mathrm{H}_{2}\right)$ plotted versus $\mathrm{CH}_{4}$ mixing ratio, which was independently determined on the samples by Marc Brass (manuscript in preparation) with errors of $\sim 1 \%$.

\section{Results}

The altitude profile of the mixing ratio of $\mathrm{H}_{2}$ and its deuterium content determined from 13 air samples collected between 12 and $33 \mathrm{~km}$ over Aire sur l'Ardour, southern France $\left(43.7^{\circ} \mathrm{N}, 0.3^{\circ} \mathrm{W}\right)$ on 24 October 2002 is shown in Fig. 2. It is known from previous studies (Ehhalt et al., 1977), that the $\mathrm{H}_{2}$ mixing ratio does not exhibit large variations throughout this altitude range. Its $\delta \mathrm{D}$ value, however, shows a pronounced increase from typical tropospheric values of about $130 \%$ at $12 \mathrm{~km}$ to more than $400 \%$ at $32.4 \mathrm{~km}$. Despite the fact that $\mathrm{H}_{2}$ is produced in the stratosphere from isotopically much more depleted $\mathrm{CH}_{4}$, it becomes actually strongly enriched.

Figure 3 shows $\delta \mathrm{D}\left(\mathrm{H}_{2}\right)$ plotted versus the $\mathrm{CH}_{4}$ mixing ratio, which is a proxy for the degree of photochemical 
processing in the stratosphere. It is evident that hydrogen gets progressively enriched in deuterium as $\mathrm{CH}_{4}$ is destroyed further. The two parameters show a very compact linear correlation $\left(\mathrm{R}^{2}=0.998\right)$. We note, however, that this does not necessarily imply a chemical connection. When we compare any two stratospheric species with local life times that are substantially longer than the transport times, their distribution is dominated by transport processes rather than chemistry, which does result in compact correlations (Plumb and Ko, 1992). We note that since this is true for both $\mathrm{H}_{2}$ and $\mathrm{CH}_{4}$ (Zöger et al., 1999), the relation presented in Fig. 3 is not only characteristic for this single time and location, but is expected to hold (with possible small variations) throughout large regions of the stratosphere. This is supported by the fact that the correlation between $\delta \mathrm{D}\left(\mathrm{H}_{2}\right)$ and $\mathrm{CH}_{4}$ mixing ratios is very similar to the one recently found by Rahn et al. (2003) at high northern latitudes. Our samples were collected at lower latitudes and up to higher altitudes, confirming that this must be a global effect.

\section{Discussion}

The strong isotope enrichments convincingly illustrate that $\mathrm{H}_{2}$ is not a mere spectator of stratospheric hydrogen cycling, but it plays an active role. Although the $\mathrm{H}_{2}$ mixing ratio is constant, there must be a continuous production and destruction of $\mathrm{H}_{2}$ to cause the observed deuterium enrichment. If we assume that the general understanding of hydrogen sources and sinks in the stratosphere is correct, this can only be due to either a faster production of HD compared to $\mathrm{HH}$ from $\mathrm{CH}_{4}$ oxidation, or a preferential destruction of $\mathrm{HH}$, or both.

In their investigation of the tropospheric hydrogen budget, Gerst and Quay (2001) have investigated this issue in detail in an endeavor to explain the high $\delta \mathrm{D}$ value of $\mathrm{H}_{2}$ in the troposphere. We will discuss our stratospheric data along the same lines, but for stratospheric conditions. The fractionation in the stratospheric $\mathrm{H}_{2}$ sinks can be quantified, since fractionation constants have been determined experimentally. The situation is less favorable for the stratospheric $\mathrm{H}_{2}$ source, i.e., production of $\mathrm{H}_{2}$ from $\mathrm{CH}_{4}$. Fractionations of large magnitude are expected to occur in several reaction steps along the reaction sequence (Fig. 1) (Gerst and Quay, 2001). Unfortunately, quantitative information is lacking for most of them, and it is not yet possible to model the transfer of deuterium through the $\mathrm{CH}_{4}$ oxidation chain. Therefore, at this stage we do not investigate the individual reaction steps and only attempt to answer the question: What isotopic composition is required for $\mathrm{H}_{2}$ produced by $\mathrm{CH}_{4}$ oxidation to explain the stratospheric observations? In the following, we name this quantity $\delta \mathrm{D}\left(\mathrm{H}_{2}\right)_{\text {source }}$ since photochemically produced $\mathrm{H}_{2}$ is the only molecular hydrogen source in the stratosphere. The aim is to determine a value for $\delta \mathrm{D}\left(\mathrm{H}_{2}\right)_{\text {source }}$ which leads to a $\delta \mathrm{D}\left(\mathrm{H}_{2}\right)-\mathrm{CH}_{4}$ correlation as shown in Fig. 3. A similar approach was also adopted by
Gerst and Quay (2001). In their study, however, the situation was different due to the unknown relative strengths of the photochemical and the soil sinks in the troposphere. In the stratosphere, only photochemistry is important.

To illustrate the role of the relevant fractionation effects in our simplified system, we carry out box model calculations. At the outset, we want to mention the limitations of using a box model for this purpose. They arise primarily due to the fact that a box model does not include effects of diffusion, transport and mixing. It has been shown, however, that these dynamical processes affect the isotopic composition of long-lived stratospheric trace gases, which are removed in the stratosphere (Röckmann et al, 2001; Kaiser et al., 2002). Generally, the "apparent" fractionation constants which can be derived from stratospheric observations are significantly lower than the kinetic fractionation constants determined in the chemical removal reactions in the laboratory (Appendix A). This is taken into account by using the apparent fractionation constants rather than the actual kinetic fractionation constants in the box model. Whereas this approach leads to realistic magnitudes of the isotope fractionation in box models, mixing is of course not treated realistically this way, because in reality mixing affects the isotope ratios by smoothing out gradients. This means that a modeled vertical profile may still include additional structure, e.g. a curvature, which is not sufficiently "smeared out", due to the inadequate way of including dynamical effects (in particular for the case of $\mathrm{H}_{2}$ which also has a stratospheric source). Thus, reliable detailed altitude profiles can only be expected from at least 1D modeling with a realistic parameterization of vertical mixing. Knowing about these limitations, we perform the following box model calculations to illustrate the individual fractionation mechanisms and to put some constraints on the isotopic composition of $\mathrm{H}_{2}$ produced from $\mathrm{CH}_{4}$ oxidation.

In our model, the starting point is always an air parcel entering the stratosphere with $1750 \mathrm{nmol} / \mathrm{mol} \mathrm{CH}_{4}$, $500 \mathrm{nmol} / \mathrm{mol} \mathrm{H}_{2}$ and $\delta \mathrm{D}\left(\mathrm{H}_{2}\right)=130 \%$. The isotopic composition of $\mathrm{CH}_{4}$ is irrelevant since we are only interested in the final product, i.e., $\delta \mathrm{D}\left(\mathrm{H}_{2}\right)_{\text {source. }}$ At each model step, a small fraction of $\mathrm{CH}_{4}$ is removed, and $\mathrm{H}_{2}$ is produced with a certain yield $y$ and isotopic composition $\delta \mathrm{D}\left(\mathrm{H}_{2}\right)_{\text {source }}$. To keep the $\mathrm{H}_{2}$ mixing ratio constant, the same amount of $\mathrm{H}_{2}$ is then removed again with the relevant fractionation constant $\alpha_{\mathrm{HD}-\text { sink. }}$. Figure $4 \mathrm{a}$ illustrates the approach for a simple example. In the first box model run (green lines), $\mathrm{H}_{2}$ is produced with $\delta \mathrm{D}\left(\mathrm{H}_{2}\right)_{\text {source }}=-80 \%$ which is the isotopic composition of tropospheric $\mathrm{CH}_{4}$, the initial source material. Fractionations in $\mathrm{H}_{2}$ sinks are not included $\left(\alpha_{\mathrm{HD}-\text { sink }}=1\right)$, thus $\delta \mathrm{D}\left(\mathrm{H}_{2}\right)_{\text {source }}$ does not change as methane mixing ratios decrease. Light hydrogen is thus transferred to the $\mathrm{H}_{2}$ reservoir and causes a considerable depletion although the mixing ratio is constant. The extent of hydrogen transfer depends on the fraction of hydrogen that is processed via $\mathrm{H}_{2}$, and we assume two cases for the $\mathrm{H}_{2}$ yield from $\mathrm{CH}_{4}$ oxidation, $y=$ 0.6 and $y=1.0$, i.e., for each $\mathrm{CH}_{4}$ molecule destroyed 0.6 


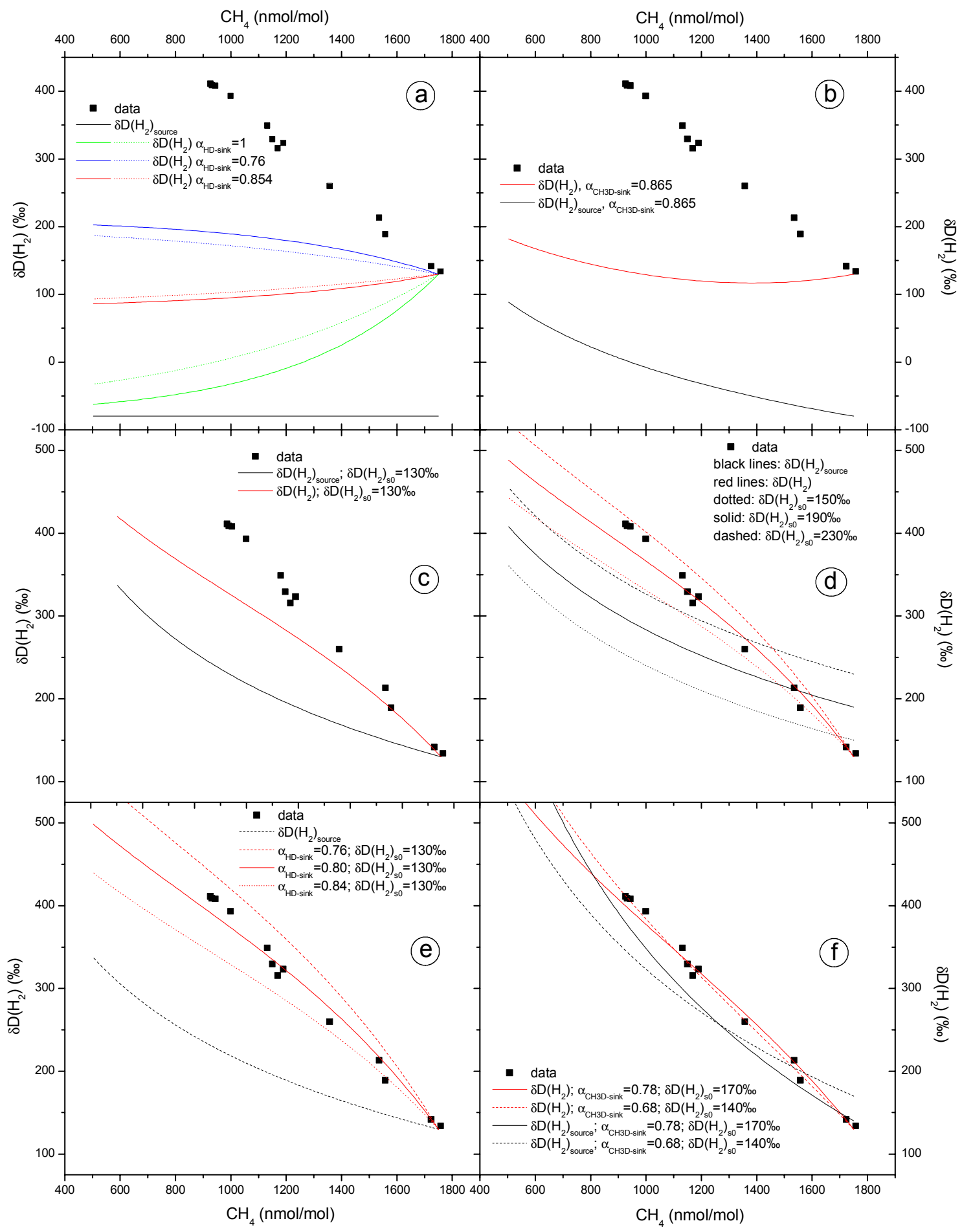

Fig. 4. Box model calculation results illustrating the effects of fractionation in hydrogen sources and sinks (a)-(c) and the sensitivity to the individual parameters (d)-(f). $\delta \mathrm{D}$ is plotted as a function of $\mathrm{CH}_{4}$ mixing ratio. (a) includes only the fractionation in the $\mathrm{H}_{2}$ removal reactions for three different fractionation constants $\alpha_{\mathrm{HD}-\text { sink }}$ and for $\mathrm{H}_{2}$ yields from $\mathrm{CH}_{4}$ of $y=1.0$ (molec $\mathrm{H}_{2} / \mathrm{molec}_{\mathrm{CH}}$ removed), solid lines and $y=0.6$ (molec $\mathrm{H}_{2} /$ molec $\mathrm{CH}_{4}$ removed), dotted lines. In (b) the change of $\delta \mathrm{D}\left(\mathrm{H}_{2}\right)$ source with $\mathrm{CH}_{4}$ mixing ratio, parameterized by $\alpha_{\mathrm{CH}_{3} \mathrm{D}-\text { sink,app }}=0.865$, is added. This leads to an enrichment of $\delta \mathrm{D}\left(\mathrm{H}_{2}\right)_{\text {source }}$ with decreasing concentration. In $(\mathrm{c}) \delta \mathrm{D}\left(\mathrm{H}_{2}\right)_{\mathrm{s} 0}=130 \%$ from Gerst and Quay is used, but even higher values of $\delta \mathrm{D}\left(\mathrm{H}_{2}\right)_{\mathrm{s} 0}=150 \%$ o to $230 \%$ (d) are necessary to bring the model results to the range of the observations. In (e) the fractionation factor for the $\mathrm{H}_{2} \operatorname{sink}, \alpha_{\mathrm{HD}-\operatorname{sink} \text {, app }}$ is varied, in (f) $\alpha_{\mathrm{CH}} \mathrm{D}-\operatorname{sink}$, app is varied. $\delta \mathrm{D}\left(\mathrm{H}_{2}\right)_{\mathrm{s} 0}$ is always adjusted to yield results that are in agreement with the observations. 
and $1 \mathrm{H}_{2}$ molecules are formed, respectively. As expected, when less hydrogen is processed via $\mathrm{H}_{2}(y=0.6)$, the transfer is smaller.

In the second step, fractionations in the $\mathrm{H}_{2}$ sinks are included. $\alpha_{\mathrm{HD}-\text { sink }}=0.76$ is an estimate for a globally weighted average of the fractionations in the two sink reactions with $\mathrm{OH}$ and $\mathrm{O}\left({ }^{1} \mathrm{D}\right)$ (Appendix $\mathrm{A}$ ), and $\alpha_{\mathrm{HD}-\text { sink,app }}=0.854$ is the apparent fractionation factor to be expected in the stratosphere under the influence of diffusive mixing (Appendix A). The substantial isotope fractionation in the removal of $\mathrm{H}_{2}$ does lead to an appreciable enrichment in the remaining $\mathrm{H}_{2}$ fraction. Nevertheless, Fig. 4a shows that the effect of the sink alone does not lead to the observed enrichments. Calculations are shown for a $\mathrm{H}_{2}$ yield of $y=0.6$ and $y=1.0$. As shown in Appendix A, $\alpha_{\text {app }}$ is considered more realistic for the stratosphere (close to diffusion limited case), and we use this value as well as $y=1.0$ in the following.

The final parameter used in the model is the change of $\delta \mathrm{D}\left(\mathrm{H}_{2}\right)_{\text {source }}$ with altitude. Since $\delta \mathrm{D}\left(\mathrm{H}_{2}\right)_{\text {source }}$ does originate from $\mathrm{CH}_{4}$, changes in the $\delta \mathrm{D}\left(\mathrm{CH}_{4}\right)$ value lead to changes in $\delta \mathrm{D}\left(\mathrm{H}_{2}\right)_{\text {source }}$. The change of $\delta \mathrm{D}\left(\mathrm{CH}_{4}\right)$ with $\mathrm{CH}_{4}$ mixing ratio in the stratosphere can be predicted from the relative ${ }^{13} \mathrm{C}$ and $\mathrm{D}$ fractionation constants for the sink reactions, observations of $\delta^{13} \mathrm{C}\left(\mathrm{CH}_{4}\right)$ changes as a function of $\mathrm{CH}_{4}$ mixing ratio and results from $2 \mathrm{D}$ modeling that are in good agreement with

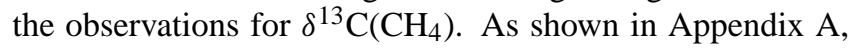
$\alpha_{\mathrm{CH}_{3} \mathrm{D}-\text { sink,app }}=0.865$ should be a realistic apparent fractionation constant taking into account diffusive mixing, with the limitations as discussed above.

It is reasonable to assume initially that the isotope fractionation between the $\mathrm{CH}_{4}$ source material and the $\mathrm{H}_{2}$ product is constant throughout the stratosphere. This means that the change of $\delta \mathrm{D}\left(\mathrm{H}_{2}\right)_{\text {source }}$ with altitude is similar to the one of $\delta \mathrm{D}\left(\mathrm{CH}_{4}\right)$ itself and can be parameterized by $\alpha_{\mathrm{CH}_{3} \mathrm{D}-\text { sink, app }}$. As a consequence, the choice of $\delta \mathrm{D}\left(\mathrm{H}_{2}\right)_{\text {source }}$ is only free at the tropopause, and we will denote this value $\delta \mathrm{D}\left(\mathrm{H}_{2}\right)_{\mathrm{s} 0}$. From this point on, $\delta \mathrm{D}\left(\mathrm{H}_{2}\right)_{\text {source }}$ will change "parallel" to $\delta \mathrm{D}\left(\mathrm{CH}_{4}\right)$. The change of $\delta \mathrm{D}\left(\mathrm{H}_{2}\right)_{\text {source }}$ relative to $\delta \mathrm{D}\left(\mathrm{H}_{2}\right)_{\mathrm{s} 0}$ (i.e. on a scale where $\delta \mathrm{D}\left(\mathrm{H}_{2}\right)_{\mathrm{s} 0}=0$ ) can then simply be calculated as a function of the $\mathrm{CH}_{4}$ mixing ratio according to $\delta \mathrm{D}\left(\mathrm{H}_{2}\right)_{\text {source }}=\left(\left[\mathrm{CH}_{4}\right] /\left[\mathrm{CH}_{4}\right]_{0}\right)^{\left(\alpha_{\mathrm{CH}_{3} \mathrm{D}-\text { sink, app }}-1\right)}-1$. Thus, $\delta \mathrm{D}\left(\mathrm{H}_{2}\right)_{\text {source }}$ increases with decreasing $\mathrm{CH}_{4}$ mixing ratio (Fig. 4b), which leads to higher stratospheric $\delta \mathrm{D}\left(\mathrm{H}_{2}\right)$ values at smaller $\mathrm{CH}_{4}$ mixing ratios.

The model is thus characterized by three parameters, namely $\alpha_{\mathrm{HD}-\text { sink, app }}, \alpha_{\mathrm{CH}_{3} \mathrm{D}-\text { sink,app }}$, and $\delta \mathrm{D}\left(\mathrm{H}_{2}\right)_{\mathrm{s} 0}$, but clearly the values chosen above cannot explain the stratospheric observations. Gerst and Quay (2001) concluded from tropospheric $\mathrm{H}_{2}$ isotope budget considerations that $\delta \mathrm{D}\left(\mathrm{H}_{2}\right)_{\text {source }}$ should be $130 \pm 70 \%$ in the troposphere to explain the high tropospheric $\delta \mathrm{D}\left(\mathrm{H}_{2}\right)$ value. If $\delta \mathrm{D}\left(\mathrm{H}_{2}\right)_{\mathrm{s} 0}=130 \%$ is used in the model, the resulting enrichments are closer to, but still lower than the observations (Fig. 4c). Figure 4d shows that keeping the other parameters constant, the high stratospheric enrichments can be modeled fairly well using $\delta \mathrm{D}\left(\mathrm{H}_{2}\right)_{\mathrm{s} 0} \approx 190 \pm 40 \%$.

In the following, the other parameters of the model are varied. In Fig. $4 \mathrm{e}, \alpha_{\mathrm{HD}-\text { sink, app }}$ is changed from the value adopted above (0.854) in three steps to $0.84,0.8$ and finally to the value in the reaction limit $(0.76)$. This is a huge change, and most likely unrealistic, as argued in Appendix A. Comparing Fig. $4 \mathrm{e}$ to $d$ shows that lowering the value of the parameter $\alpha_{\mathrm{HD}-\text { sink,app }}$ has a similar effect as increasing $\delta \mathrm{D}\left(\mathrm{H}_{2}\right)_{\mathrm{s} 0}$. Thus, when $\alpha_{\mathrm{HD}-\text { sink, app }}$ is decreased sufficiently the model results are in the range of the observations already for $\delta \mathrm{D}\left(\mathrm{H}_{2}\right)_{\mathrm{s} 0}=130 \%$.

In Fig. 4f the change in $\delta \mathrm{D}\left(\mathrm{H}_{2}\right)_{\text {source }}$ with altitude, parameterized by the value $\alpha_{\mathrm{CH}_{3} \mathrm{D}-\text { sink, app }}$, is varied. Note again that changes in $\alpha_{\mathrm{CH}_{3} \mathrm{D}-\text { sink, app }}$ do not imply a change in the fractionation associated with $\mathrm{CH}_{4}$ oxidation, but only characterize the product $\mathrm{H}_{2}$. Fractionations in other individual reaction steps in the $\mathrm{CH}_{4}$ oxidation sequence can cause an altitude dependence of $\delta \mathrm{D}\left(\mathrm{H}_{2}\right)_{\text {source }}$ that varies from the

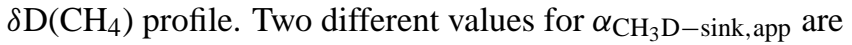
chosen, 0.78 , the value under reaction limited conditions and an even lower value of $0.68 . \delta \mathrm{D}\left(\mathrm{H}_{2}\right)_{\mathrm{s} 0}$ is adjusted again to yield results close to the measurements. Satisfactory agreement with the observations is achieved for $\delta \mathrm{D}\left(\mathrm{H}_{2}\right)_{\mathrm{s} 0}=170 \%$ o and $140 \%$ respectively. In these runs parameters are chosen such that $\delta \mathrm{D}\left(\mathrm{H}_{2}\right)_{\text {source }}$ varies much more strongly with altitude (Fig. 4f). Interestingly, the curvature in the modeled stratospheric profile disappears, which indicates that it strongly depends on the isotopic composition of the $\mathrm{H}_{2}$ source. In fact, a good agreement of the modeled $\delta \mathrm{D}\left(\mathrm{H}_{2}\right)$ profile and the data is obtained if the profiles of $\delta \mathrm{D}\left(\mathrm{H}_{2}\right)_{\text {source }}$ and $\delta \mathrm{D}\left(\mathrm{H}_{2}\right)$ are rather similar. As explained above, precise agreement between the altitude profile of our box model runs and the observations is not expected, due to the fact that stratospheric mixing is only taken into account by adjusting the fractionation constants. In reality we expect mixing processes to remove some of the curvature seen in the calculated correlations.

Regarding the value of $\delta \mathrm{D}\left(\mathrm{H}_{2}\right)_{\mathrm{s} 0}$ the model calculations show a quite consistent picture. Including all the sensitivity tests, which cover a wide range, values of $\delta \mathrm{D}\left(\mathrm{H}_{2}\right)_{\mathrm{s} 0}$ between $130 \% o$ and $230 \%$ are required to reproduce the stratospheric observations. If we assume that $\delta \mathrm{D}\left(\mathrm{H}_{2}\right)_{\mathrm{s} 0}$, the deuterium content of $\mathrm{H}_{2}$ produced from $\mathrm{CH}_{4}$ near the tropopause is similar to $\delta \mathrm{D}\left(\mathrm{H}_{2}\right)_{\text {source }}$ in the troposphere, then this range can also be adopted for the troposphere. Thus the stratospheric data constrain the range of $130 \pm 70 \%$ o for photochemically produced $\mathrm{H}_{2}$ predicted by Gerst and Quay (2001) based on tropospheric $\mathrm{H}_{2}$ budget calculations to the upper half. A reduction of the range of the deuterium content of photochemically produced $\mathrm{H}_{2}$ by a factor of two puts a major constraint on the global $\mathrm{H}_{2}$ budget (Gerst and Quay, 2001).

The range of 130 to $230 \%$ for $\delta \mathrm{D}\left(\mathrm{H}_{2}\right)_{\mathrm{s} 0}$ as derived in the box model runs indicates that an overall isotope enrichment of roughly 240 to $350 \%$ occurs in the oxidation sequence 
Table 1. Rate coefficients (in $\mathrm{cm}^{3}$ molecule ${ }^{-1} \mathrm{~s}^{-1}$ ) for the reaction of $\mathrm{H}_{2}$ and $\mathrm{HD}$ with $\mathrm{O}\left({ }^{1} \mathrm{D}\right)$ and $\mathrm{OH}$ for stratospherically relevant temperatures from (Talukdar et al., 1996; Talukdar and Ravishankara, 1996) and the corresponding fractionation factors.

\begin{tabular}{ccc}
\hline & $k(230 \mathrm{~K})$ & $\alpha(230 \mathrm{~K})$ \\
\hline $\mathrm{O}\left({ }^{1} \mathrm{D}\right)+\mathrm{H}_{2}$ & $1.1 \times 10^{-10}$ & \\
$\mathrm{O}\left({ }^{1} \mathrm{D}\right)+\mathrm{HD}$ & $1.1 \times 10^{-10}$ & 1.00 \\
\hline $\mathrm{OH}+\mathrm{H}_{2}$ & $9.2 \times 10^{-16}$ & \\
$\mathrm{OH}+\mathrm{HD}$ & $4.75 \times 10^{-16}$ & 0.52 \\
\hline
\end{tabular}

from $\mathrm{CH}_{4}$ with $\delta \mathrm{D}=-86 \%$ o to the final $\mathrm{H}_{2}$ product (note that $\delta$ values do not add linearly), in good agreement with the results found by Rahn et al. (2003). This massive enrichment must originate from one or more individual reaction steps in the $\mathrm{CH}_{4}$ oxidation sequence (Fig. 1). Unfortunately, little quantitative information about the individual reaction steps is available, which prevents a detailed investigation at present. As discussed in (Gerst and Quay, 2001), at least in the initial hydrogen abstraction step of the $\mathrm{CH}_{4}$ oxidation sequence (Fig. 1), $\mathrm{H}$ is expected to be removed preferentially, which would cause a deuterium enrichment in the final reaction product $\mathrm{H}_{2}$. For more details, the reader is referred to Gerst and Quay (2001) where all available isotope information about the reaction sequence is provided.

\section{Conclusions}

High precision $\delta \mathrm{D}$ measurements on stratospheric $\mathrm{H}_{2}$ reveal a pronounced deuterium enrichment that increases with degree of photochemical processing in the stratosphere. An approximately linear relationship between $\delta \mathrm{D}\left(\mathrm{H}_{2}\right)$ and $\mathrm{CH}_{4}$ concentration is found with $\delta \mathrm{D}$ values increasing from $130 \%$ o near the tropopause up to $400 \%$ at $\mathrm{CH}_{4}$ mixing ratios of $900 \mathrm{nmol} / \mathrm{mol}$. The deuterium enrichments demonstrate that stratospheric molecular hydrogen plays an important role in the stratospheric deuterium budget and has to be included in global budget calculations. Box model calculations show that to explain the enrichment, $\mathrm{H}_{2}$ produced from $\mathrm{CH}_{4}$ oxidation must be strongly enriched vs. the $\mathrm{CH}_{4}$ source material, in agreement with conclusions from tropospheric (Gerst and Quay, 2001) and stratospheric (Rahn et al., 2003) measurements, and the value near the tropopause can be tightly constrained to $\delta \mathrm{D}\left(\mathrm{H}_{2}\right)_{\mathrm{s} 0}=(180 \pm 50) \%$ o.

\section{Appendix A}

5.1 Fractionation constants in the stratosphere

The two major sinks of $\mathrm{H}_{2}$ in the stratosphere are reaction with $\mathrm{OH}$ and $\mathrm{O}\left({ }^{1} \mathrm{D}\right)$, with only a minor contribution from
Table 2. Fractionation constant for the $\mathrm{CH}_{4}$ removal reactions from (Saueressig et al., 2001), globally averaged removal strengths for the different radicals derived from model calculations (C. Brühl, pers. comm.), and the calculated globally averaged fractionation constant.

\begin{tabular}{ccc}
\hline reactant & share of total removal & $\alpha(230 \mathrm{~K})$ \\
\hline $\mathrm{OH}$ & $41 \%$ & 0.735 \\
$\mathrm{O}\left({ }^{1} \mathrm{D}\right)$ & $32 \%$ & 0.943 \\
$\mathrm{Cl}$ & $28 \%$ & 0.626 \\
\hline \multicolumn{2}{c}{ global average $\alpha_{\mathrm{CH}_{3} \mathrm{D}-\text { sink }}$} & 0.778 \\
\hline
\end{tabular}

$\mathrm{Cl}$ (LeTexier et al., 1988). The relevant isotope effects have been determined and are listed in Table 1. Whereas there is no kinetic fractionation in the reaction $\mathrm{O}\left({ }^{1} \mathrm{D}\right)+\mathrm{H}_{2}$, the reaction $\mathrm{OH}+\mathrm{H}_{2}$ proceeds almost twice as fast as $\mathrm{OH}+\mathrm{HD}$ at typical stratospheric temperatures of $230 \mathrm{~K}$. The global average stratospheric removal rate of $\mathrm{H}_{2}$ by $\mathrm{OH}$ is similar to that by $\mathrm{O}\left({ }^{1} \mathrm{D}\right)$ (LeTexier et al., 1988). Thus the globally averaged kinetic fractionation factor is the average of the two individual fractionation factors, thus $\alpha_{\mathrm{HD}-\mathrm{sink}} \approx 0.76$.

In the stratosphere, $\mathrm{CH}_{4}$ is removed by the three radicals $\mathrm{OH}, \mathrm{O}\left({ }^{1} \mathrm{D}\right)$ and $\mathrm{Cl}$. The relevant reactions have been characterized isotopically (Saueressig et al., 1996; Saueressig et al., 2001). Table 2 lists the fractionation constants for stratospheric temperatures. All oxidants preferentially remove light $\mathrm{CH}_{4}$, and the remaining methane gets enriched. The relative shares of the three removal reactions can be obtained from model calculations of stratospheric $\mathrm{CH}_{4}$ isotope ratios. Before the first high precision measurements of $\delta \mathrm{D}$ in $\mathrm{CH}_{4}$ became available very recently (Rice et al., 2003), constraints for models (Bergamaschi et al., 1996; Saueressig et al., 2001) were based on $\delta^{13} \mathrm{C}\left(\mathrm{CH}_{4}\right)$ observations (Sugawara et al., 1997), which could be modeled well for global average removal rates of $41 \%$ oxidation by $\mathrm{OH}, 31 \%$ oxidation by $\mathrm{O}\left({ }^{1} \mathrm{D}\right)$ and $28 \%$ oxidation by $\mathrm{Cl}(\mathrm{C}$. Brühl, pers. comm.). A large set of new measurements (M. Braß et al., manuscript in preparation) confirms these numbers. The weighted global average fractionation constant for $\mathrm{H}$ abstraction from $\mathrm{CH}_{4}$ is thus $\alpha_{\mathrm{CH}_{3} \mathrm{D}-\mathrm{sink}}=0.78$.

However, due to the effects of turbulent diffusion, the apparent (i.e. observed) fractionation factors $\alpha_{\text {app }}$ in the stratosphere are significantly smaller than the ones of the removal reactions themselves (Röckmann et al., 2001). Kaiser et al. (2002) showed that for long-lived trace gases that are removed in the stratosphere, $\alpha_{\text {app }}$ ranges from $\alpha$ in the reaction limited case to $\sqrt{\alpha}$ in the diffusion limited case. Theoretical arguments for using apparent rather than actual fractionation constants also for a trace gas like $\mathrm{H}_{2}$, which has a source in the stratosphere, will be discussed in a future publication (Kaiser et al., manuscript in preparation). Also, mixing of air masses with different isotopic composition decreases the apparent fractionations. 
Table 3. Global average fractionation constants for the removal of $\mathrm{CH}_{4}$ and $\mathrm{H}_{2}$ in reaction limited conditions $(\alpha)$, diffusion limited conditions $(\sqrt{\alpha})$, and the best estimate for a realistic $\alpha_{\text {app }}$ in the stratosphere.

\begin{tabular}{cccc}
\hline & $\alpha$ & $\sqrt{\alpha}$ & $\alpha_{\text {app }}$ \\
\hline $\mathrm{H}_{2}$ sink & 0.76 & 0.872 & 0.854 \\
$\mathrm{CH}_{4}$ sink & 0.778 & 0.882 & 0.865 \\
\hline
\end{tabular}

A comparison of reaction rate constants calculated by the 2D model (C. Brühl, pers. comm.) and vertical eddy diffusion coefficients (Froidevaux and Yung, 1982) indicates that the stratospheric situation is in between the pure diffusion limited and reaction limited cases. Thus, to estimate suitable apparent fractionation constants we use the comparison of available laboratory fractionation data and stratospheric measurements. Comparison of laboratory and stratospheric isotope measurements for $\mathrm{N}_{2} \mathrm{O}$ (Röckmann et al., 2001) demonstrate that we are close to the diffusion limited case in the lower and middle stratosphere. Also $\delta^{13} \mathrm{C}\left(\mathrm{CH}_{4}\right)$ measurements show that the apparent fractionation factor $\alpha_{13 \mathrm{CH}_{4}-\text { sink, app }} \approx 0.985$ (Sugawara et al., 1997) is significantly larger than $\alpha_{13 \mathrm{CH}_{4}-\text { sink, app }} \approx 0.975$, the removal rate weighted fractionation constant for the three sinks, and close to $\sqrt{\alpha_{13 \mathrm{CH}_{4}-\text { sink }}}=0.987$, the value under diffusion limited conditions. In Table 3, our best estimates for stratospheric apparent fractionation constants in the removal reactions of $\mathrm{CH}_{4}$ and $\mathrm{H}_{2}$ are shown. They are closer to the diffusion limited value, based on the observations of $\delta^{13} \mathrm{C}$ in $\mathrm{CH}_{4}$. These numbers are used as starting values in the box model calculations presented in this paper. We note that the value of 0.865 for $\mathrm{CH}_{4}$ removal obtained this way is in good agreement with the average fractionation constant from the recently published first series of high precision measurements (Rice et al., 2003). Variations of the apparent fractionation factors with altitude (Rice et al., 2003), which may arise due to altitudinal variations in the removal rates of $\mathrm{H}_{2}$ and $\mathrm{CH}_{4}$ by the individual radical reactions are not included in the model.

Acknowledgements. We thank J. Mak for help with the development of the analytical system. J. Kiko provided the Helium compressor used in the analytical system. $\mathrm{CH}_{4}$ concentration measurements were obtained by Marc Brass, together with ${ }^{13} \mathrm{C}\left(\mathrm{CH}_{4}\right)$ data (manuscript in preparation). Ingeborg Levin kindly provided her independent $\mathrm{CH}_{4}$ concentration data which were used to validate our own $\mathrm{CH}_{4}$ concentration measurements. We are indebted to Christel Facklam and Ingeborg Levin for isotopic calibration of our mass spectrometer working standard $\mathrm{H}_{2}$. C. Brühl provided his model results on stratospheric removal rates of $\mathrm{CH}_{4}$ by the three individual sinks. We thank J. Kaiser for valuable discussion in particular regarding fractionation constants in the stratosphere and we thank K. Mauersberger, C. A. M. Brenninkmeijer and J. Kaiser for helpful comments on the manuscript.

\section{References}

Bergamaschi, P., Brühl, C., Brenninkmeijer, C. A. M., Saueressig, G., Crowley, J. N., Grooss, J. U., Fischer, H., and Crutzen, P. J.: Implications of the large carbon kinetic isotope effect in the reaction $\mathrm{CH}_{4}+\mathrm{Cl}$ for the ${ }^{13} \mathrm{C} /{ }^{12} \mathrm{C}$ ratio of stratospheric $\mathrm{CH}_{4}$, Geophys. Res. Lett., 23, 2227-2230, 1996.

Blake, D. R. and Rowland, F. S.: Continuing Worldwide Increase in Tropospheric Methane, 1978 to 1987, Science, 239, 1129-1131, 1988.

Dlugokencky, E. J., Masarie, K. A., Lang, P. M., and Tans, P. P.: Continuing decline in the growth rate of the atmospheric methane burden, Nature, 393, 447-450, 1998.

Ehhalt, D. H., Schmidt, U., and Heidt, L. E.: Vertical Profiles of Molecular-Hydrogen in the Troposphere and Stratosphere, J. Geophys. Res., 82, 5907-5911, 1977.

Engel, A., Schiller, C., Schmidt, U., Borchers, R., Ovarlez, H., and Ovarlez, J.: The total hydrogen budget in the Arctic winter stratosphere during the European Arctic Stratospheric Ozone Experiment, J. Geophys. Res., 101, 14 495-14 503, 1996.

Etheridge, D. M., Pearman, G. I., and Fraser, P. J.: Changes in tropospheric methane between 1841 and 1978 from high accumulation-rate Antarctic ice core, Tellus, 44B, 181-294, 1992.

Evans, S. J., Toumi, R., Harries, J. E., Chipperfield, M. P., and Russell, J. M.: Trends in stratospheric humidity and the sensitivity of ozone to these trends, J. Geophys. Res., 103, 8715-8725, 1998.

Forster, P. M. D. and Shine, K. P.: Assessing the climate impact of trends in stratospheric water vapor, Geophys. Res. Lett., 29, 10.1029/2001GL013909, 2002.

Froidevaux, L. and Yung, Y. L.: Radiation and Chemistry in the Stratosphere - Sensitivity to $\mathrm{O}_{2}$ Absorption Cross-Sections in the Herzberg Continuum, Geophys. Res. Lett., 9, 854-857, 1982.

Gerst, S. and Quay, P.: The deuterium content of atmospheric molecular hydrogen: Method and initial measurements, J. Geophys. Res., 105, 26433-26 445, 2000.

Gerst, S. and Quay, P.: Deuterium component of the global molecular hydrogen cycle, J. Geophys. Res., 106, 5021-5031, 2001.

Hagemann, R., Nief, G., and Roth, E.: Absolute isotopic scale for deuterium analysis of natural waters, Tellus, 22, 712-715, 1970.

Irion, F. W., Moyer, E. J., Gunson, M. R., Rinsland, C. P., Yung, Y. L., Michelsen, H. A., Salawitch, R. J., Chang, A. Y., Newchurch, M. J., Abbas, M. M., Abrams, M. C., and Zander, R.: Stratospheric observations of $\mathrm{CH}_{3} \mathrm{D}$ and HDO from ATMOS infrared solar spectra: Enrichments of deuterium in methane and implications for HD, Geophys. Res. Lett., 23, 2381-2384, 1996.

Kaiser, J., Brenninkmeijer, C. A. M., and Röckmann, T.: Intramolecular ${ }^{15} \mathrm{~N}$ and ${ }^{18} \mathrm{O}$ fractionation in the reaction of $\mathrm{N}_{2} \mathrm{O}$ with $\mathrm{O}\left({ }^{1} \mathrm{D}\right)$ and its implications for the stratospheric $\mathrm{N}_{2} \mathrm{O}$ isotope signature, J. Geophys. Res., 107, 10.1029/2001JD001506, 2002.

Kuang, Z. M., Toon, G. C., Wennberg, P. O., and Yung, Y. L.: Measured $\mathrm{HDO} / \mathrm{H}_{2} \mathrm{O}$ ratios across the tropical tropopause, Geophys. Res. Lett., 30, 10.1029/2003GL017023, 2003.

LeTexier, H., Solomon, S., and Garcia, R. R.: The role of molecular hydrogen and methane oxidation in the water vapour budget of the stratosphere, Q. J. R. Meteorol. Soc., 114, 281-295, 1988.

Oltmans, S. J. and Hofmann, D. J.: Increase in lower-stratospheric water vapour at a mid-latitude Northern Hemisphere site from 1981 to 1994, Nature, 374, 146-149, 1995. 
Plumb, R. A. and Ko, M. K. W.: Interrelationships between Mixing Ratios of Long Lived Stratospheric Constituents, Journal of Geophysical Research-Atmospheres, 97, 10 145-10 156, 1992.

Quay, P., Stutsman, J., Wilbur, D., Snover, A., Dlugokencky, E., and Brown, T.: The isotopic composition of atmospheric methane, Glob. Biogeochem. Cycl., 13, 445-461, 1999.

Rahn, T., Eiler, J. M., Boering, K. A., Wennberg, P. O., McCarthy, M. C., Tyler, S., Schauffler, S., Donnelly, S., and Atlas, E.: Extreme deuterium enrichment in stratospheric hydrogen and the global atmospheric budget of $\mathrm{H}_{2}$, Nature, 424, 918-921, 2003.

Rahn, T., Kitchen, N., and Eiler, J. M.: D/H ratios of atmospheric $\mathrm{H}_{2}$ in urban air: Results using new methods for analysis of nanomolar $\mathrm{H}_{2}$ samples, Geochim. Cosmochim. Acta, 66, 2475-2481, 2002.

Rice, A. L., Tyler, S. C., McCarthy, M. C., Boering, K. A., and Atlas, E.: Carbon and hydrogen isotopic compositions of stratospheric methane: 1. High-precision observations from the NASA ER-2 aircraft, J. Geophys. Res., 108, doi:10.1029/2002JD003042, 2003.

Röckmann, T., Kaiser, J., Brenninkmeijer, C. A. M., Crowley, J. N., Borchers, R., Brand, W. A., and Crutzen, P. J.: Isotopic enrichment of nitrous oxide $\left({ }^{15} \mathrm{~N}^{14} \mathrm{NO},{ }^{14} \mathrm{~N}^{15} \mathrm{NO},{ }^{14} \mathrm{~N}^{14} \mathrm{~N}^{18} \mathrm{O}\right)$ in the stratosphere and in the laboratory, J. Geophys. Res., 106, $10403-$ $10410,2001$.

Saueressig, G., Bergamaschi, P., Crowley, J. N., Fischer, H., and Harris, G. W.: D/H kinetic isotope effect in the reaction $\mathrm{CH}_{4}+\mathrm{Cl}$, Geophys. Res. Lett., 23, No. 24, 3619-3622, 1996.
Saueressig, G., Crowley, J. N., Bergamaschi, P., Brühl, C., Brenninkmeijer, C. A. M., and Fischer, H.: Carbon 13 and D kinetic isotope effects in the reactions of $\mathrm{CH}_{4}$ with $\mathrm{O}\left({ }^{1} \mathrm{D}\right)$ and $\mathrm{OH}$ : New laboratory measurements and their implications for the isotopic composition of stratospheric methane, J. Geophys. Res., 106, 23 127-23 138, 2001.

Schmidt, U., Kulessa, G., Klein, E., Roth, E. P., Fabian, P., and Borchers, R.: Intercomparison of Balloon-Borne Cryogenic Whole Air Samplers During the Map-Globus 1983 Campaign, Planet. Space Sci., 35, 647-656, 1987.

Sugawara, S., Nakazawa, T., Shirakawa, Y., Kawamura, K., and Aoki, S.: Vertical profile of the carbon isotopic ratio of stratospheric methane over Japan, Geophys. Res. Lett., 24, 29892992, 1997.

Talukdar, R. K., Gierczak, T., Goldfarb, L., Rudich, Y., Rao, B. S. M., and Ravishankara, A. R.: Kinetics of hydroxyl radical reactions with isotopically labeled hydrogen, Journal of Physical Chemistry, 100, 3037-3043, 1996.

Talukdar, R. K. and Ravishankara, A. R.: Rate coefficients for $\mathrm{O}\left({ }^{1} \mathrm{D}\right)+\mathrm{H}_{2}, \mathrm{D}_{2}, \mathrm{HD}$ reactions and $\mathrm{H}$ atom yield in $\mathrm{O}\left({ }^{1} \mathrm{D}\right)+\mathrm{HD}$ reaction, Chemical Physics Letters, 253, 177-183, 1996.

Tromp, T. K., Shia, R.-L., Allen, M., Eiler, J. M., and Yung, Y. L.: Potential Environmental Impact of a Hydrogen Economy on the Stratosphere, Science, 300, 1740-1742, 2003.

Zöger, M., Engel, A., McKenna, D. S., Schiller, C., Schmidt, U., and Woyke, T.: Balloon-borne in situ measurements of stratospheric $\mathrm{H}_{2} \mathrm{O}, \mathrm{CH}_{4}$ and $\mathrm{H}_{2}$ at midlatitudes, J. Geophys. Res., 104, 1817-1825, 1999. 